\title{
PENGARUH PENGGUNAAN APLIKASI GOOGLE MAPS TERHADAP MINAT BELAJAR GEOGRAFI PESERTA DIDIK DI SMA NEGERI KOTA LANGSA
}

\author{
Zidan Sihotang ${ }^{1 *}$, Taufik Hidayat ${ }^{2}$ \\ ${ }^{1,2}$ Program Studi Pendidikan Geografi, FKIP, Universitas Samudra \\ *sihotangzidan22@email.com, taufikhdayt17@gmail.com
}

\begin{tabular}{|c|c|}
\hline \multicolumn{2}{|c|}{ INFO ARTIKEL } \\
\hline \multicolumn{2}{|c|}{ Riwayat Artikel: } \\
\hline Dikirim & : $\quad 23-06-2021$ \\
\hline Disetujui & : $12-08-2021$ \\
\hline Diterbitkan & : $13-08-2021$ \\
\hline
\end{tabular}

Kata kunci:

Google Maps, Minat Belajar, Geografi

\begin{abstract}
ABSTRAK
This research aimed to analyse regression relationship between the use of Google Maps Application on the interest of students in learning geography at high school. This research was done in survey method with population of state high school students in Langsa City. Sampling technique used was random stratified sampling. The data then analysed using IBMI SPSS 22 by operating linear regression analysis. The results showed that using Google Maps Application has significant effect on student's learning interest in subject of geography at state high schools in Langsa City. It was evidenced with the value of $F_{\text {count }}=41.583>3.160$ or $\left(F_{\text {count }}>F_{\text {table }}\right)$, so that $H_{0}$ was rejected and $H_{1}$ was accepted. It meant that there was a positive and significant influence of Google Maps Application use on interest of students in learning geography. Therefore, the researchers recommend the teachers / educators to use Google Maps Application in learning geography in order to improve the interest and learning outcomes of students in geography.
\end{abstract}

Penelitian ini bertujuan untuk menganalisis hubungan regresi antara penggunaan aplikasi Google Maps terhadap minat belajar Geografi peserta didik di SMA . Penelitian ini merupakan penelitian survey dengan populasi peserta didik SMA Negeri di Kota Langsa . Teknik Sampling yang di gunakan adalah Random Stratiffed Sampling . Data dianalisis menggunakan IBM SPSS 22 melalui analisis regresi linier. Hasil penelitian menunjukkan bahwa Penggunaan Aplikasi Google Maps berpengaruh secara signifikan terhadap minat belajar peserta didik pada mata pelajaran Geografi di SMA Negeri Langsa . Hal ini dibuktikan dengan nilai F hitung $=41.583>3.160$ atau ( $\mathrm{F}$ hitung $>\mathrm{F}$ tabel) sehingga $\mathrm{H} 0$ di tolak dan $\mathrm{H} 1$ diterima. Yang artinya terdapat pengaruh posistif dan signifikan Penggunaan Aplikasi Google Maps terhadap minat belajar Geografi Peserta Didik. Sehingga Peneliti merekomendasikan para guru/para pengajar untuk memanfaatkan penggunaan Aplikasi Google Maps dalam pembelajaran Geografi untuk meningkatkan minat dan hasil belajar Geografi peserta didik. 


\section{PENDAHULUAN}

Peranan mata pelajaran Geografi dalam pendidikan adalah untuk dapat mengembangkan pengetahuan siswa tentang pemahaman tempat- tempat, pengelompokan lokasi, masyarakat dan lingkungan pada alam di permukaan bumi. Melalui pelajaran Geografi, siswa didorong untuk dapat memahami tentang lokasi, kenampakan muka bumi, dengan kemampuan peserta didik untuk memahami bahwa manusia menciptakan wilayah (region) untuk menyederhanakan kompleksistas muka bumi dengan mengetahui, karakteristik dan persebaran lokasi ekologis di muka bumi, proses-proses fisik yang membentuk kenampakan alam dan gambaran dari muka bumi.

Dalam pengertian di atas dapat kita ketahui betapa pentingnya ilmu geografi terhadap kehidupan karena kondisi alam dan karakteristik permukaan bumi selalu berubah. Sehingga perlu di tumbuhkannya minat belajar geografi peserta didik karena minat merupakan ketertarikan atau pada suatu hal tanpa ada rasa paksaan. Untuk menumbuhkan minat adalah dengan membantu peserta didik melihat bagaimana keterkaitan / hubungan antara materi yang diekspetasikan untuk di pelajari dirinya sendiri.

Untuk menumbuhakan minat belajar geografi di perlukan suatau metode yang bisa merangsang daya imajinasi siswa agar tertarik untuk mempelajari geografi salah satu cara efektif dan efesien dalam mempelajari geografi adalah dengan mampu menampilkan bentuk geografis muka bumi dengan tampilan visualisasi digital melalui media pembelajaran yang interaktif. Dari pernyataan di atas menjadi latar belakang peneliti dalam membuat penelitian ini.

Peneliti akan melakukan survey sejauh mana siswa SMA Negeri Langsa dalam mengunakan Aplikasi Google Maps yang terdapat dalam smartphone, karena dalam era globalisasi sekarang peserta didik tidak akan terlepas yang namanya smartphone selain adanya aplikasi google maps smartphone juga dapat memudahkan siswa dalam memahami materi seperti fitur fitur internet didalamnya yang mempermudah mencari data mau artikel didalamnya. Dan juga penggunaan smartphone telah menjadi kebutuhun pokok dalam kehidupan sehari hari untuk itu perlu ide untuk menjawab tantangan tersebut yaitu dengan memanfaatkan aplikasi yang terdapat dalam smartphone itu sendiri.

Aplikasi Google Maps merupakan salah satu aplikasi yang terdapat di dalam smartphone yang bisa digunakan untuk media pembelajaran Geografi karena beberapa fitur yang dimilikinya seperti peta Default, Citra Satelit, Medan lokasi, yang dapat digunakan untuk mengetahui berbagai informasi yang berkaitan dengan kenampakan bumi , lingkungan , pola pola muka bumi, kondisi wilayah suatu daerah, kontur, dan informasi lainnya Google Maps memberikan layanan (service) yang diberikan oleh Google kepada para pengguna untuk memanfaatkan Google Maps dalam mengembangkan aplikasi dan penggunaan aplikasi ini menggunakan akses internet dan proses yang mudah dalam penggunaannya.

Di Kota Langsa mata pelajaran Geografi merupakan pelajaran yang wajib untuk peserta didik di SMA khususnya dengan jurusan IPS ( Ilmu Pendidikan Sosial). Peneliti melakukan survey secara langsung di seluruh sekolah SMA Negeri di Kota Langsa. Dari Survey tersebut, peneliti mendapatkan informasi bahwa guru mata pelajaran Geografi di sekolah tersebut, masih sering menggunakan media buku ataupun peta atlas daripada media yang lebih menarik lainya dalam proses pembelajaran di sekolah.

Hal ini yang menyebabkan proses pembelajaran yang membuat peserta didik merasa bosan, hal tersebut bukan berarti peserta didik tidak menyukai pembelajaran geografi namun bagaimana media pembelajaran yang digunakan oleh guru dalam menyampaikan materi agar minat belajar dan imajinasi siswa dapat berkembang untuk mengkaji hal- hal baru yang terdapat di Aplikasi Google Maps.

Kalau dilihat dari letak Kota Langsa yang sangat dekat dengan Kota Medan akses informasi sangat bagus dalam kota ini dan penggunaan akses internet yang cukup tinggi hal ini yang menjadi potensi sebagai penunjang minat peserta didik dalam menggunakan Aplikasi Google Maps tersebut kalau dimanfaatkan secara bijak oleh guru dan peserta didik siswa Sekolah Menengah atas di Kota Langsa diperkenankan untuk membawa smartphone di sekolah dalam mempermudah 
siswa untuk mencari informasi dan belajar, namun sebagian siswa tidak memahami dan memanfaatkan aplikasi yang terdapat dalam smartphone mereka kebanyakan peserta didik hanya manfaatkan sebagai kesenangan pribadi saja.

Selain itu, jika dilihat dari fitur- fitur yang terdapat dalam Aplikasi Google Maps dalam media pembelajaran bisa sangat membantu dan bermanfaat dalam proses pembelajaran sehingga dapat menambah minat belajar peserta didik. Kurangnya minat belajar dapat di pengaruhi oleh faktor Internal (Siswa dan Keluarga) dan eksternal (sekolah) faktor eksternal yang mencakup : 1) Metode Mengajar, 2) Relasi Siswa dengan Siswa, 3)Relasi Guru dengan siswa, 4)Displin Sekolah dan 5.) Media Belajar.

Media belajar menjadi hal pokok penting yang harus dikembangkan agar minat belajar khusunya geografi dapat di tingkatkan. Penggunaan Aplikasi Google Maps dapat mempermudah siswa dalam pembelajaran kalau tepat dalam penerapanya, karena kebanyakan guru sejauh ini hanya mengunakan metode ceramah dan media buku dalam proses pembelajaran. Hal ini bukan disebabkan adanya sebagian guru tidak mengerti cara menggunakan Aplikasi Google Maps tetapi masih minimnya guru dalam mengajar dengan menggunakan media tersebut, meskipun sekolah sudah memiliki fasilitas yang cukup baik. Hal ini yang mengakibatkan kurangnya hasil belajar siswa tersebut.

Materi yang terdapat pada materi pelajaran Geografi SMA kebanyakan akan menganalisis tentang bentuk muka bumi seperti materi Persebaran Wilayah, Tata Ruang Kota, Struktur Bumi (Kontur) Perpetaan (Kartografi), Penginderaan Jauh, Sistem Informasi Geografis (SIG), dan masih banyak lagi. Pada materi tersebut, guru dalam melakukan pembelajaran masih banyak bersifat konvensional, artinya guru masih mendominasi jalannya pembelajaran dan belum memanfaatkan media pembelajaran secara maksimal sehingga pembelajaran yang dilakukan cenderung kurang menarik untuk siswa. Selain itu, guru belum sepenuhnya memanfaatkan alat peraga yang berbasis teknologi karena masih berkutat pada alat peraga standar saja seperti Peta, Atlas atau Globe.
Dari uraian di atas, Penelitian ini bertujuan untuk mengetahui tingkat pengaruh penggunaan aplikasi Google Maps terhadap minat belajar peserta didik pada mata pelajaran Geografi di SMA Negeri di Kota Langsa.

\section{METODE PENELITIAN}

Metode penelitian yang digunakan dalam penelitian ini adalah Survei. Dengan cara pendekatan kuantitatif untuk menjelaskan atau mengambarkan suatu masalah yang hasilnya dapat digeneralisasikan. " sehingga Peneliti lebih mementingkan aspek keleluasaan data dari pada kedalaman data atau analisis sehingga data atau hasil riset dianggap merupakan representasi dari seluruh populasi " (Kriyantono, 2008) dalam Penelitian ini peneliti membagikan angket kepada siswa dalam beberapa pernyataan berupa pernyataan tentang Penggunaan aplikasi google maps dan minat belajar siswa tentang geografi yang berjumlah 20 pernyataan dalam satu individu.

Adapaun Populasi penelitian ini adalah 70 peserta didik di SMA Negeri kota Langsa dengan kriteria sebagai berikut: 1. Bersekolah di SMA Negeri Langsa. 2. Siswa SMA dengan jurusan IPS Dari kelas XI dan kelas XII. Populasi yang berjumlah 70 Responden dan satu Responden akan mengisi pernyataan berjumlah 20 butir pernyataan .20 pernyaataan tersebut terdiri dari 10 variable $\mathrm{x}$ yaitu penggunaan aplikasi google maps dan 10 variable y yaitu minat belajar geografi pesetra didik.

Teknik sampling yang digunakan oleh peneliti adalah teknik probability sampling tipe Proportitionate Stratified Random Sampling. Proportionate Stratified Random Sampling merupakan teknik sampling yang digunakan bila populasi mempunyai anggota/unsur yang Heterogen dan berstrata secara proporsional (Sugiyono, 2008). Dengan demikian sampel dalam penelitian ini adalah bagian dari populasi penelitian, yaitu 70 Peserta didik dari 7 sekolah negeri di kota Langsa. Metode pengumpulan data dengan mengajukan pernyataan kepada responden melalui sejumlah daftar pernyataan guna mengumpulkan informasi mengenai permasalahan yang sedang diteliti dengan menyebarkan 70 angket ke 7 sekolah negeri yang ada di Kota langsa.

Untuk penelitian ini data yang di analisis dalam pengujian Hipotesis adalah 
dengan Menggunakan menggunakan Uji $\mathrm{T}$ Untuk Dua sampel Bebas (Independent Sampel $\mathrm{T}$ Test) diuji independent Sampel $\mathrm{T}$ Test digunakan untuk mengetahui ada tidaknya perbedaan rata-rata antara dua kelompok sampel yang berpengaruh. Namun dalam penelitian ini dapat dibuktikan bahwa uji nilai

\section{Sub Judul}

Penelitian survei ini dilaksanakan di seluruh SMA Negeri yang ada di Kota Langsa. Kegiatan survei ini dilakukan untuk mengawali penelitian terhadap peserta didik di kelas, yang bertujuan untuk mengetahui Pengaruh Penggunaan Aplikasi Google Maps terhadap minat belajar Geografi peserta didik di SMA Negeri Kota Langsa. Kegiatan survei dilakukan oleh Mahasiswa pendidikan

geografi Yang dibantu oleh para guru dan peserta didik yang berpasrtisipasi dalam penelitian ini (Andrasmoro \& Nurlaila, 2018).

Kegiatan pembelajaran siswa SMA Negeri di Kota Langsa selama proses belajar dengan pengaruh penggunaan aplikasi google maps terhadap minat belajar geografi yang diperoleh
T dengan hasil nilai .000 membuktikan adanya pengaruh 37\% penggunaan aplikasi Google Maps terhadap minat belajar Geografi peserta didik dan $63 \%$ di pengaruhi oleh faktor lain lain.

\section{HASIL DAN PEMBAHASAN}

dengan menggunakan 70 angket dengan cara mengisi angket yang telah disebar. Angket yang disebar berisikan pertanyaan dan pernyataan yang dibuat sesuai dengan variabel yang ada (Jaya \& Ramli, 2017).

Analisis regresi linear yang diperoleh pada penelitian ini yaitu Pengaruh Penggunaan Aplikasi Google Maps. Analisis regresi linear dilakukan dengan bantuan perhitungan IBM SPSS Statistics 24. Dalam menentukan besar, pengaruh atau prediksi variabel independent (X) dengan variabel dependent (Y) dilakukan dengan melihat hasil output di SPSS. Untuk menggambarkan variabel penelitian tersebut, disajikan tabel berupa tabel Model Sumarry dan Coefficients. Berdasarkan survei yang telah dilakukan oleh peneliti, dapat dilihat pada tabel analisis regresi linear di bawah ini:

Tabel 1. Hasil Pengolahan Data Koefisien Determinasi Variabel Pengaruh Penggunaan Aplikasi Google Maps (X)

\begin{tabular}{|c|c|c|c|c|}
\hline Model & R & $\begin{array}{c}\text { R. } \\
\text { Square }\end{array}$ & Adjusted R Square & $\begin{array}{c}\text { Std. Error of the } \\
\text { Estimate }\end{array}$ \\
\hline 1 & $.616^{\mathrm{a}}$ & .379 & .370 & 4.929 \\
\hline
\end{tabular}

Berdasarkan tabel 1, nilai $\mathrm{R}^{2} \quad 0,379$ menunjukkan bahwa variable penggunaan aplikasi google maps berpengaruh sebesar $37 \%$ terhadap minat belajar geografi dan $63 \%$ dipengaruhi oleh fakto-faktor lain.

Tabel 2. Hasil Uji T Variabel Minat Belajar Geografi (Y) Coefficients ${ }^{\mathrm{a}}$

\begin{tabular}{|c|c|c|c|c|c|}
\hline \multirow{2}{*}{ Model } & \multicolumn{2}{|c|}{$\begin{array}{c}\text { Unstandardized } \\
\text { Ceofficients }\end{array}$} & $\begin{array}{c}\text { Standardized } \\
\text { Ceofficients }\end{array}$ & \multirow{2}{*}{$\mathrm{T}$} & Sig \\
\cline { 2 - 6 } & $\mathrm{B}$ & Std. Error & Beta & & \\
\hline $\begin{array}{c}\text { (Constant) Terhadap } \\
\text { Minat } \\
\text { Belajar Geogarfi }\end{array}$ & 17.899 & 3.589 & .616 & 4.987 & .000 \\
& .590 & .091 & & 6.449 & .000 \\
\hline
\end{tabular}

Dependent Variabel: Minat Belajar Geografi (Y)

Uji t pada tabel 2 tentang pengaruh penggunaan aplikasi google maps terhadap minat belajar geografi (Y) antara lain:

a. Data hasil pengujian statistic diperoleh hasil t hitung < t tabel yaitu 6,449>2,0017 dapat di artikan 
adanya pengaruh positif penggunaan aplikasi google maps (X) terhadap Minat Belajar Geografi.

b. Tingkat signifikan sebesar ,000 >0,005 sehingga dapat diartikan terdapat pengaruh signifikan penggunaan aplikasi google maps terhadap minat belajar $(\mathrm{Y})$

c. Penarikan Kesimpulan

d. Karena hasil hitung nilai t positif, maka dapat disimpulkan bahwa dengan taraf signifikansi 0,005 secara parsial pengaruh penggunaan aplikasi google maps (X) Memiliki pengaruh positif dan signifikan terhadap minat belajar geografi (Y) pada SMA Negeri di Kota Langsa. Jadi ,semakin seringnya penggunaan aplikasi google maps dalam pembelajarn semakin meningkatnya minat belajar geografi peserta didik untuk belajar geografi.

\section{Uji Simultan}

Untuk menguji pengaruh variable Pengaruh penggunaan aplikasi google maps (X1) terhadap Minat Belajar Geografi (Y) dengan dilakukan dengan uji statistic F (uji simultan). Sebagai pembanding untuk mengukur pengaruh signifikan, maka digunakan kriteria signifikan 5\% $(0,05)$ dan membandingkan antara Fhitung dengan Ftabel dengan ketentuan sebagai berikut:

a.) Jika F hitung $<\mathrm{F}$ table : berarti H0 Diterima dan

H1 di tolak $(\alpha=5 \%)$

b.) Jika F hitung > F tabel : berarti H0 Ditolak dan H1

diterima $(\alpha=5 \%)$

Ftabel $=3,160$, adapun hasil pengolahan data F mengunakan SPSS versi 22, dengan hasil sebagai berikut:

\begin{tabular}{|c|c|c|c|c|c|}
\hline Model & Sum of Squares & Df & Mean Square & F & Sig \\
\hline 1. Regression & 1010.084 & 1 & 1010.084 & 41.583 & N $.000^{\mathrm{a}}$ \\
Residual Total & 1651.759 & 68 & 24.291 & & \\
\hline
\end{tabular}

Tabel 3. Anova b

a) Predictors: (Constant), Terhadap Minat Belajar Geografi

b) Dependent Variabel: Pengaruh kegunaan Google Maps

Dari Tabel di atas di peroleh nilai $\mathrm{F}=41.538>3,160$ atau ( $\mathrm{F}$ hitung.$>\mathrm{F}$ tabel) Artinya terdapat pengaruh positif dan signifikan secara simultan antara pengaruh penggunaan google maps (X) secara simultan terhadap minat belajar geografi (Y) di SMA Negeri Langsa.

\section{SIMPULAN}

Berdasarkan hasil pelaksanaan penelitian serta analisis yang telah dilakukan dan pembahas pembahasan yang dijelaskan pada bab sebelumnya dapat disimpulkan bahwa :

a) Secara Parsial penggunaan aplikasi google masp dalam pambelajaran geografi memberikan pengaruh kepada minat belajar geografi di SMA Negeri
Langsa hal ini di buktikan dengan nilai signifikansi pada uji t yang kurang dari 0,005

b) Secara Simultan penggunaan aplikasi google masp dalam pambelajaran geografi memberikan pengaruh kepada minat belajar geografi di SMA Negeri Langsa hal ini di buktikan dengan nilai signifikansi pada uji t yang kurang dari 


\section{0,005}

c) Variabel Pengunaan aplikasi Google maps (X) mempunyai pengaruh positif terhadap minat belajar geografi Peserta didik $(\mathrm{Y})$ dengan nilai $\mathrm{F}$ hitung $>\mathrm{F}$ tabel sebesar $41.583>3,160$ dan nilai koefesien determinasi sebesar 0,379 atau sebesar $37 \%$. Yang aritnya Independent Variabel (X) Penggunaan aplikasi google maps berpengaruh dengan dependent Variabel (Y) sebesar 37\% dan sisanya $63 \%$ di pengaruhi oleh faktor Lainya yang dapat di jelaskan oleh peneliti lain.

Pengaruh penggunaan aplikasi google maps berpengaruh terhadap minat belajara siswa dalam mata pelajaran geografi karena fitur yang terdapat dalam google maps bisa menunjang minat dan hasil belajar peserta didik karena seperti kita ketahui penggunaan smartphone dalam kehidupan sehari sehari tidak bisa dipisahkan dan menjadi kebutuhan pokok termasuk peserta didik itu sendiri. untuk itu karena pembelajaran geografi yang mudah dan interaktif adalah pembelajaran yang bisa menampilkan visialisai digital dari bentuk geografis muka bumi. Dan bisa dibuktikan dengan analisis di atas.

\section{REKOMENDASI}

Dalam rangka memperbaiki pelaksanaan tindakan berikutnya dan guna meningkatkan Minat pembelajaran geografi di sekolah, maka penulis mengajukan beberapa saran sebagai berikut :

a) Pembelajaran dengan menggunakan Google Maps merupakan salah satu alternatif yang layak dikembangkan untuk mengatasi masalah rendahnya minat dan hasil belajar pada mata pelajaran Geografi.

b) Persiapan guru untuk melaksanakan pembelajaran yang mampu menampilkan visualisasi digital dari bentuk geografis muka bumi dengan menggunakan aplikasi google maps dalam pembelajaran geografi.

\section{DAFTAR PUSTAKA}

Crampton, J. W. (2009). Cartography: Maps 2.0. Progress in Human Geography, 33(1), 91-100. https://doi.org/10.1177/0309132508094 074

Ervina, E., Asyik, B., \& Mizwar, D. (n.d.). Pengaruh Penggunaan Media Google Earth dan Peta Terhadap Peningkatan Hasil Belajar Geografi Pada Materi Kawasan Asia Tenggara DI SMA Negeri 14 Bandar Lampung Tahun Pelajaran 2011/2012. 7 .

Goodchild, M. F. (2009). Geographic information systems and science: Today and tomorrow. Annals GIS, 15(1), 3-9. https://doi.org/10.1080/1947568090325 0715

Hardianti, S., Abdi, A. W., \& Harun, M. Y. (2017). Penggunaan Multimedia Smartphone untuk Meningkatkan Hasil Belajar Geografi Kelas XI IPS di SMA Laboratorium UNSYIAH Banda Aceh. Jurnal Ilmiah Mahasiswa Pendidikan Geografi FKIP Unsyiah, 2(3), 11.

Huda, F. (2014). Penggunaan Media Peta Untuk Meningkatkan Hasil Belajar Siswa Pada Mata Pelajaran Ilmu Pendidikan sosial Sekolah Dasar. Jurnal pendidikan sekolah dasar, 02(3), 9.

Joyce, K. E., Belliss, S. E., Samsonov, S. V., McNeill, S. J., \& Glassey, P. J. (2009). A review of the status of satellite remote sensing and image processing techniques for mapping natural hazards and disasters. Progress in Physical Geography: Earth and Environment, 33(2),

183-207. https://doi.org/10.1177/0309133309339 563

Kriyantono, R. (2008). Teknik Praktis riset Komunikasi. Jakarta: Kencana prenada Media group.

Leydesdorff, L., \& Rafols, I. (2009). A global map of science based on the ISI subject categories. Journal of the American Society for Information Science and Technology, 60(2), 348-362. https://doi.org/10.1002/asi.20967

Mahdia, F., \& Noviyanto, F. (2013). Pemanfaatan Google Maps API Untuk Pembangunan Sistem Informasi Manajemen Bantuan Logistik Pasca Bencana Alam Berbasis Mobile Web. Jurnal Sarjana Teknik Informatika, 1(1), 10.

Meyzilia, A., \& Ruhimat, M. (2019). Minat belajar geografi siswa kelas XII SMA Negeri se-Kabupaten Bangka tahun 
2018. jurnal Pendidikan Geografi Universitas Pendidikan Indonesia, 2(1), 9. https://doi.org/DOI:http://dx.doi.org/10/ 1797/um017v24i12019p025

Siagian, S., \& Lingin, L. (2013). Pengembangan Media Pembelajaran Interaktif Pada Mata Pelajaran Geografi. Jurnal Teknologi Pendidikan (JTP), 5(1). https://doi.org/10.24114/jtp.v5i1.487

Singarimbun, M. (2002). Metode Penelitian Survei. Jakarta: LP3S.

Siskawati, M. (2016). Pengembangan Media Pembelajaran Monopoli Untuk Meningkatkan Minat Belajar Geografi Siswa. Jurnal studi sosial FKIP Universitas Lampung, 4(1), 9.
Sugiyono. (2008). Metode Penelitian Kuantitatif, Kualitatif dan $r \& d$. Bandung: Alfabeta.

Suhandi, D. (2016). Studi Komparatif Penggunaan Media Peta Tematik dengan Media CD Interaktif Terhadap Keterampilan Berpikir kritis Bahan Ajar Pola Kegiatan Ekonomi Penduduk, Penggunaan Lahan, dan Pola Pemukiman (Studi Kasus SMP Negeri 1 Haurwangi Kabupaten Cianjur). Jurnal Geografi Gea, 13(2), 12. https://doi.org/10.17509/gea.v13 i2.3393 